\title{
Degradation Characteristics of Oil Degrading Candida tropicalis
}

\author{
Ya-Bin Zhan1, Fang-Min $\mathrm{Li}^{2}$, Wei-Chu Yu2 ${ }^{2}$, Tao Jiang3*, Li-An Ma"\# \\ ${ }^{1}$ College of Life Science, Yangtze University, Jingzhou, China \\ ${ }^{2}$ College of Chemical and Environmental Engineering, Yangtze University, Jingzhou, China \\ ${ }^{3}$ College of Animal Science, Yangtze University, Jingzhou, China \\ Email:1766784675@qq.com, ${ }^{*}$ jiangtao@yangtzeu.edu.cn, ${ }^{\#}$ malian@yangtzeu.edu.cn
}

How to cite this paper: Zhan, Y.-B., Li, F.-M., Yu, W.-C., Jiang, T. and Ma, L.-A. (2017) Degradation Characteristics of Oil Degrading Candida tropicalis. Open Access Library Journal, 4: e4090. https://doi.org/10.4236/oalib.1104090

Received: October 30, 2017

Accepted: November 11, 2017

Published: November 14, 2017

Copyright () 2017 by authors and Open Access Library Inc.

This work is licensed under the Creative Commons Attribution International License (CC BY 4.0).

http://creativecommons.org/licenses/by/4.0/

\begin{abstract}
Objective: The aim of study is to research the degradation characteristics of oil degrading Candida tropicalis (G-94). Methods: Effects of temperature, $\mathrm{pH}$, oil concentration, salt concentration, inoculation amount, $\mathrm{N}$ and $\mathrm{P}$ source on the oil removal rate of G-94 were studied by single factor test. Meanwhile, the effects of temperature, $\mathrm{pH}$, oil concentration and salt concentration on the oil removal rate of G-94 were optimized by orthogonal design. Result: The orthogonal design showed that the oil removal rate of G-94 could reach $25.83 \%$, $28.56 \%$ and $30.90 \%$ at $10 \mathrm{~d}, 20 \mathrm{~d}$ and $40 \mathrm{~d}$ under the optimal conditions which was $25^{\circ} \mathrm{C}$, initial pH 8.0, oil concentration $1.0 \%$, salt concentration $0.4 \%$, inoculum amount $4 \%$, the optimal $\mathrm{N}$ and $\mathrm{P}$ were $\left(\mathrm{NH}_{4}\right)_{2} \mathrm{SO}_{4}$ and $\mathrm{K}_{2} \mathrm{HPO}_{4}$. Conclusion: This experiment studied the degradation characteristics of G-94, which paved the way for the remediation of petroleum contaminated soil.
\end{abstract}

\section{Subject Areas \\ Environmental Sciences}

\section{Keywords}

Degrading Yeast, Candida tropicalis, Oil Degrading

\section{Introduction}

Oil contains many highly concentrated toxic materials, and oil contamination can negatively influence soil microbes and plants, as well as contaminate groundwater, which may be used for drinking or agriculture [1]. To eliminate these pollution compounds, processes have been developed based on physicochemical techniques, including the vacuum extraction of hydrocarbons, soil 
washing, electrokinetic incineration and recovery using solvents [2]. However, these methods produce toxic remnants that need to be decontaminated, which involve a high economic cost that is an obstacle to implementation [3] [4]. Fortunately, bioremediation is the microbial degradation of organic pollutants such as petroleum in soil and groundwater. This technique has the benefits of high treatment efficiency, low cost, relatively quick action, in site and ex site application, and compatibility with other techniques [5] [6] [7] [8].

Thus, in order to get insight of the bioremediation process of hydrocarbon in Qianjiang Guanghua Oilfield, the present study focused on degradation characteristics of indigenous hydrocarbon-degrading Candida tropicalis (G-94) with regards to the conditions for optimizing their activities and the efficient cleanup of the hydrocarbon pollutants.

\section{Materials and Methods}

\subsection{Source of Isolation}

The G-94 was isolated from Qianjiang Guanghua Oilfield on June 2015, stored in the laboratory of College of Life Science, Yangtze University [9].

\subsection{Growth Study}

Experiments were conducted in the oil medium described above with $0.5 \%$ oil (w/v) as sole carbon and energy source. Growth was monitored by measuring optical density at $420 \mathrm{~nm}$ with a TU-1900 spectrophotometer [10].

\subsection{Determination of Oil Removal Rate}

The oil removal rate was determined by gravimetric method [10]. A total of 80 $\mathrm{ml}$ methylene chloride was added to the oil triangle bottle to extract the oil. The water in the oil was dried at room temperature until the anhydrous sodium sulfate column was removed, until the organic solvent completely evaporated. Place the oil in the vacuum drying box at $40^{\circ} \mathrm{C}$ and keep the vacuum at $0.04 \mathrm{Mpa}$ for $30 \mathrm{~min}$. Then remove it and leave it in the dryer for $30 \mathrm{~min}$ and to weigh. The oil removal rate is calculated according to the formula (1):

$$
D=\frac{\left(C_{0}-C S\right)}{C_{0}} \times 100 \%
$$

$D$ : The oil removal rate, $\% ; C_{0}$ : blank hydrocarbon concentration, $\mathrm{mg} / \mathrm{L} ; C S$ : concentration of petroleum hydrocarbon in the culture fluid, mg/L [10].

\subsection{Study on Degradation Characteristics}

\subsubsection{Single Factor Test}

The yeast was inoculated into potato sucrose liquid medium. The yeast were inoculated in logarithmic phase, centrifuged, removed supernatant, washed with sterile normal saline, and adjusted to $\mathrm{OD}_{420}=9.185$. In the basic culture medium at the same time, by changing the growth conditions in different temperature, $\mathrm{pH}$, oil concentration, salt concentration, inoculation amount, $\mathrm{N}$ source, $\mathrm{P}$ 
source on a horizontal shaker $(150 \mathrm{rpm})$ at $35^{\circ} \mathrm{C}$ in $100 \mathrm{ml}$ oil medium for $5 \mathrm{~d}$. Learning the suitable growth conditions of G-94 by the determination of biomass $\left(\mathrm{OD}_{420}\right)$.

\subsubsection{Orthogonal Test}

Four factors and 3 levels orthogonal test (Table 1) was carried out with temperature, $\mathrm{pH}$, oil concentration and salt concentration. With $4 \%$ inoculation on a horizontal shaker $(150 \mathrm{rpm})$ in $100 \mathrm{ml}$ oil medium for $5 \mathrm{~d}$. Learning the optimum growth condition of G-94 by the determination of biomass $\left(\mathrm{OD}_{420}\right)$.

\subsubsection{Verification Test}

Under orthogonal optimum conditions, the oil removal rate of G-94 was measured at 10, 20 and 40 day, respectively.

\subsubsection{Statistic Analysis}

SAS software was used to test the significance difference $(P<0.05)$ and extremely significant difference $(P<0.01)$.

\subsection{Determination of Growth Curve}

Under the optimum conditions, the strain of G-94 was injected into the oil medium with $4 \%$ inoculum, drawing the growth curve by measuring its $\mathrm{OD}_{422}$.

\section{Results and Analysis}

\subsection{Physiology}

\subsubsection{Single Factor Test}

\section{1) Temperature}

The biomass of G-94 was effected by temperature as shown in Figure 1. The biomass decreased with the increase of temperature. There were larger biomass of G-94, when the temperature were $25^{\circ} \mathrm{C}\left(\mathrm{OD}_{420}=1.622\right)$ and $30^{\circ} \mathrm{C}\left(\mathrm{OD}_{420}=\right.$ 1.537). Compared with other treatments, there were significant differences.

Extremely significant difference $(P<0.01)$; Significance difference $(P<0.05)$. Same as below.

\section{2) $\mathrm{pH}$}

The biomass of G-94 was effected by $\mathrm{pH}$ as shown in Figure 2. The biomass increased firstly and decreased lastly with the increase of $\mathrm{pH}$. There was larger biomass of G-94, when the $\mathrm{pH}$ was $7.5\left(\mathrm{OD}_{420}=0.960\right), 8.0\left(\mathrm{OD}_{420}=1.183\right)$ and $9.0\left(\mathrm{OD}_{420}=0.991\right)$. Compared with other treatments, there were extremely significant differences.

Table 1. Factor levels table.

\begin{tabular}{ccccc}
\hline & $\mathrm{A}\left({ }^{\circ} \mathrm{C}\right)$ & $\mathrm{B}$ & $\mathrm{C}(\%)$ & $\mathrm{D}(\%)$ \\
\hline 1 & 25 & 7.8 & 0.1 & 0.3 \\
2 & 28 & 8.0 & 0.2 & 0.4 \\
3 & 30 & 8.2 & 0.3 & 0.5 \\
\hline
\end{tabular}

A: Temperature; B: pH; C: oil concentration; D: salt concentration. 


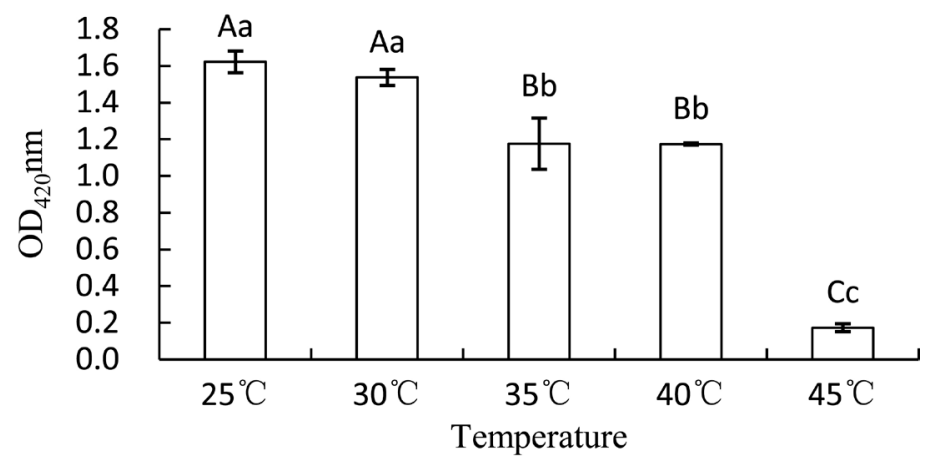

Figure 1. Biomass of G-94 under different temperature.

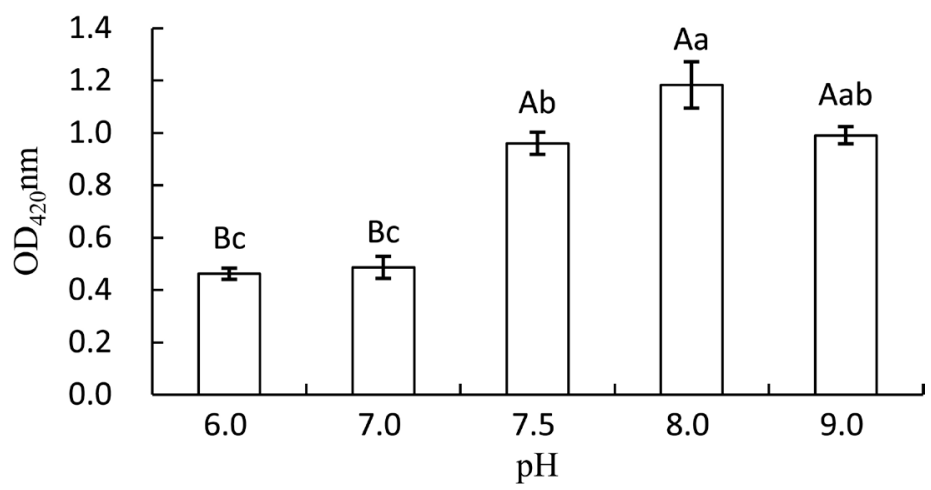

Figure 2. Biomass of G-94 under different $\mathrm{pH}$.

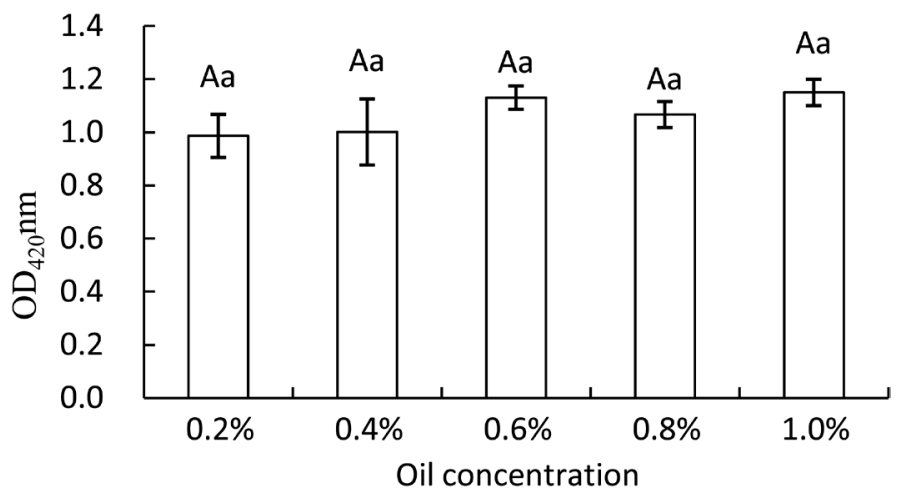

Figure 3. Biomass of G-94 under different oil concentration.

\section{3) Oil concentration}

The biomass of G-94 was effected by oil concentration as shown in Figure 3. There were larger biomass of G-94, when the oil concentration were $1.0 \%\left(\mathrm{OD}_{420}\right.$ $=1.150$ ). Compared with the biomass of oil concentrate $0.2 \%, 0.4 \%, 0.6 \%$ and $0.8 \%$, there were no significant differences.

\section{4) Salinity}

The biomass of G-94 was effected by salt concentration as shown in Figure 4 . The biomass increased firstly and decreased lastly with the increase of salt concentration. There were larger biomass of G-94, when the salt concentration was $0.4 \%\left(\mathrm{OD}_{420}=1.722\right)$. Compared with other treatments, there were extremely significant differences. 


\section{5) Inoculation amount}

The biomass of G-94 was effected by inoculation amount as shown in Figure 5. The biomass increased with the increase of inoculation amount. There was larger biomass of G-94, when the inoculation amount were $4 \%\left(\mathrm{OD}_{420}=1.739\right)$. Compared with other treatments, there were no extremely significant differences.

\section{6) Nitrogen}

The biomass of G-94 was effected by nitrogen source as shown in Figure 6 . There were larger biomass of G-94, when the nitrogen source were $\left(\mathrm{NH}_{4}\right)_{2} \mathrm{SO}_{4}$ $\left(\mathrm{OD}_{420}=0.593\right), \mathrm{NH}_{4} \mathrm{NO}_{3}\left(\mathrm{OD}_{420}=1.314\right)$ and $\mathrm{NH}_{4} \mathrm{NO}_{3}\left(\mathrm{OD}_{420}=1.175\right)$. Compared with the biomass of $\mathrm{NH}_{4} \mathrm{Cl}$ and $\mathrm{KNO}_{3}$, there were extremely significant differences.

\section{7) Phosphorus}

The biomass of G-94 was effected by phosphorus source as shown in Figure 7 . There were larger biomass of G-94, when the phosphorus source were $\mathrm{K}_{2} \mathrm{HPO}_{4}$ $\left(\mathrm{OD}_{420}=1.356\right)$. Compared with the biomass of $\mathrm{K}_{2} \mathrm{HPO}_{4}, \mathrm{Na}_{2} \mathrm{HPO}_{4}$ and $\mathrm{NaH}_{2} \mathrm{PO}_{4}$, there were extremely significant differences.

\subsubsection{Orthogonal Test}

Different conditions had obvious influence on the oil removal rate of G-94. The maximum range of temperature is the key factor affecting the oil removal rate of

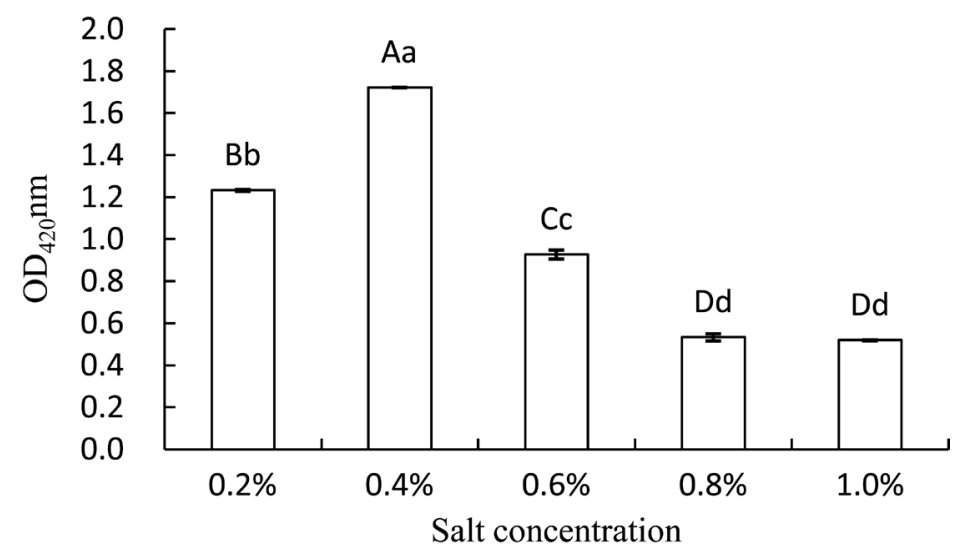

Figure 4. Biomass of G-94 under different salt concentration.

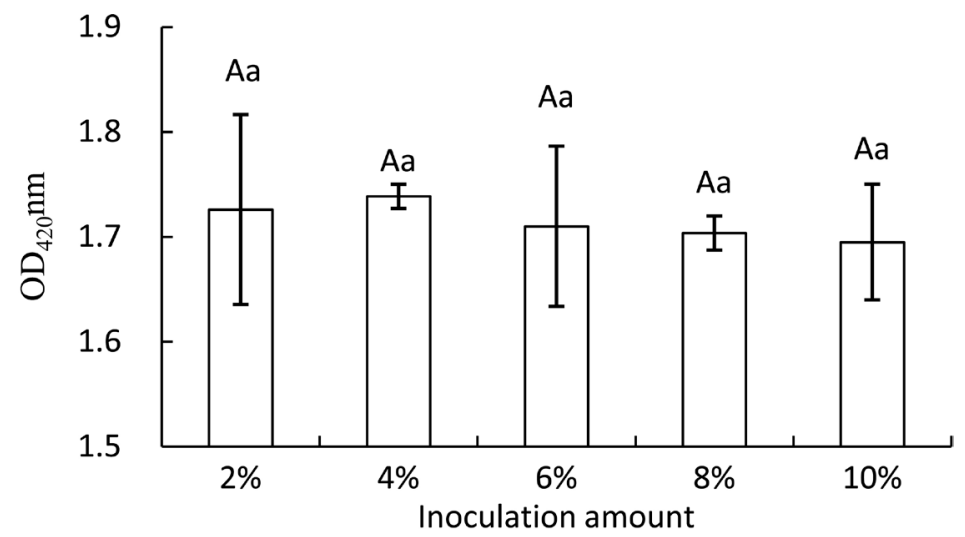

Figure 5. Biomass of G-94 under different inoculation amount. 


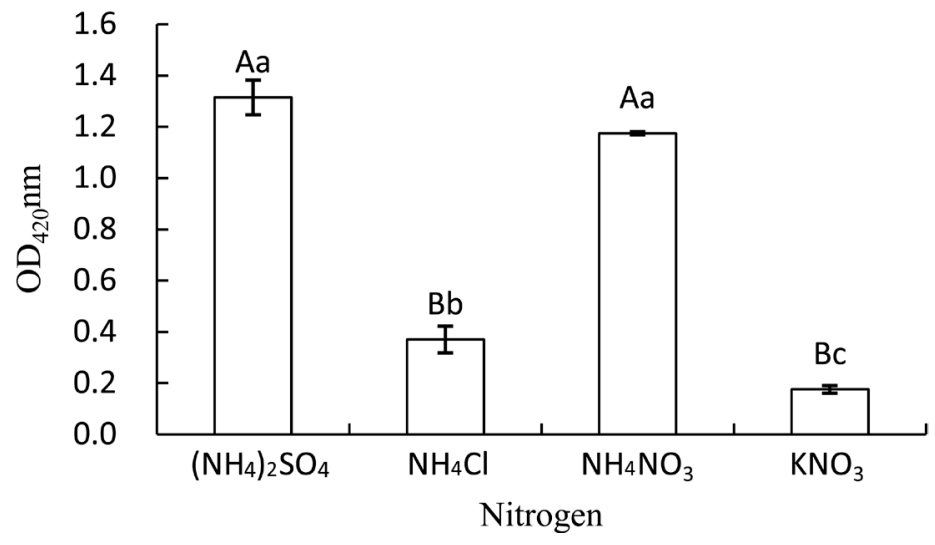

Figure 6. Biomass of G-94 under different nitrogen source.

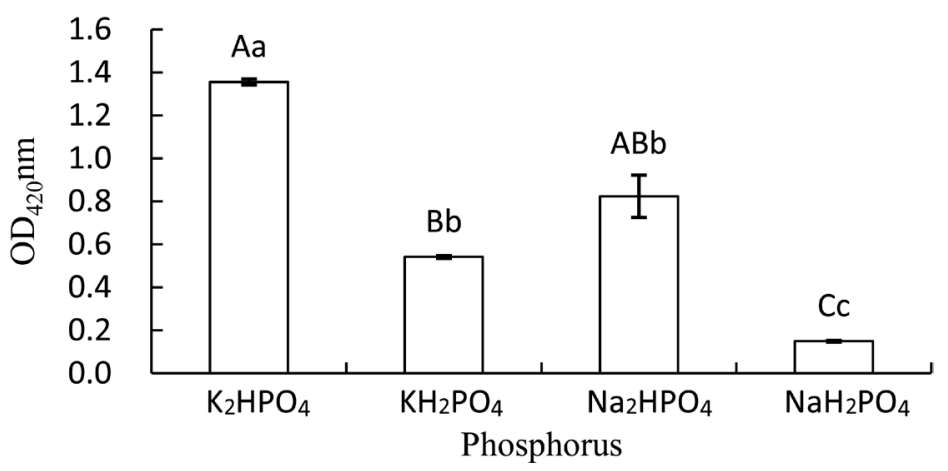

Figure 7. Biomass of G-94 under different phosphorus source.

Table 2. The orthogonal design and analysis of G-94.

\begin{tabular}{cccccc}
\hline Treatment & $\mathrm{A}\left({ }^{\circ} \mathrm{C}\right)$ & $\mathrm{B}$ & $\mathrm{C}(\%)$ & $\mathrm{D}(\%)$ & Result \\
\hline 1 & 25 & 7.8 & 0.1 & 0.3 & 1.197 \\
2 & 25 & 8.0 & 0.2 & 0.4 & 1.183 \\
3 & 25 & 8.2 & 0.3 & 0.5 & 1.544 \\
4 & 28 & 7.8 & 0.2 & 0.5 & 1.468 \\
5 & 28 & 8.0 & 0.3 & 0.3 & 1.589 \\
6 & 28 & 8.2 & 0.1 & 0.4 & 1.025 \\
7 & 30 & 7.8 & 0.3 & 0.4 & 1.537 \\
8 & 30 & 8.0 & 0.1 & 0.5 & 1.066 \\
9 & 30 & 8.2 & 0.2 & 0.3 & 1.264 \\
$\mathrm{~K} 1$ & 1.308 & 1.401 & 1.096 & 1.350 & \\
$\mathrm{~K} 2$ & 1.361 & 1.279 & 1.305 & 1.248 & \\
$\mathrm{~K} 3$ & 1.289 & 1.278 & 1.557 & 1.359 & \\
$\mathrm{R}$ & 0.072 & 0.123 & 0.467 & 0.111 & \\
\hline
\end{tabular}

A: Temperature; B: $\mathrm{pH}$; C: oil concentration; D: salt concentration.

G-94, followed by $\mathrm{pH}$ and oil concentration, while salt concentration has the least influence. Therefore, the suitable condition of oil removal rate of G-94 was $\mathrm{A}_{2} \mathrm{~B}_{1} \mathrm{C}_{3} \mathrm{D}_{3}$ which was $28^{\circ} \mathrm{C}, \mathrm{pH} 7.8$, oil concentration $0.3 \%$, salt concentration $0.5 \%$ (Table 2). 


\subsubsection{Verification Test}

The results of Verification test were shown in Figure 8. Under orthogonal optimum conditions, the oil removal rate of G-94 reached to $25.83 \%, 28.56 \%$ and $30.90 \%$ at 10,20 and 40 day, respectively.

\subsection{Determination of Growth Curve}

The result of determination of growth curve was shown in Figure 9. The 0 - 0.5 day was the lag phase of G-94; In this period, the reason why no biomass increase is that bacteria were first introduced into a fresh media. The 0.5 - 4 day was the exponential of G-94; In this period, the strain rapidly propagated and gradually turned the oil medium to muddy. The 4.5 - 13 day was the stationary phase of G-94; In this period, death rate = rate of reproduction of G-94 and continues for a long time.

\section{Discussion and Conclusion}

\subsection{Discussion}

The optimal oil removal condition of G-94 was determined through biomass of petroleum degradation microorganism, not the oil removal rate. The reason why we use the biomass is that biomass is positively correlated with degradation rate and it is more convenient than oil removal rate [10].

Candida tropicalis used to repair potato starch wastewater [11], produce xylitol [12] and Long Chain Dicarboxylic Acid [13]. There were few reports about Candida tropicalis degrading oil.

A strain of G-94 with petroleum as the sole carbon source was isolated from

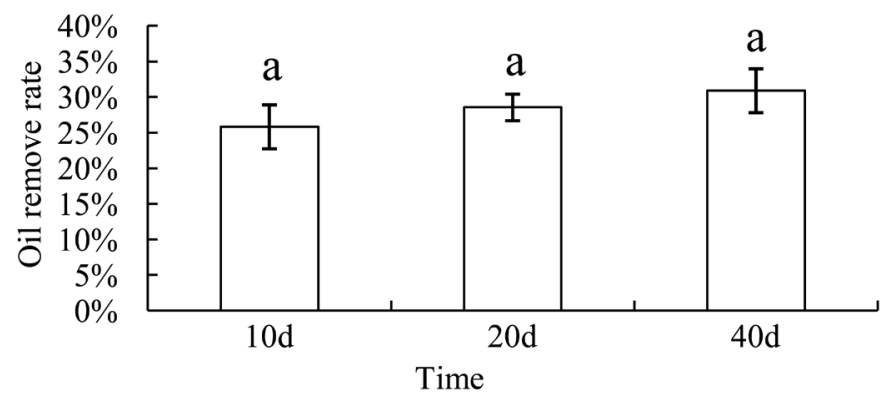

Figure 8. Oil degradation rate of strain G-94 on different time.

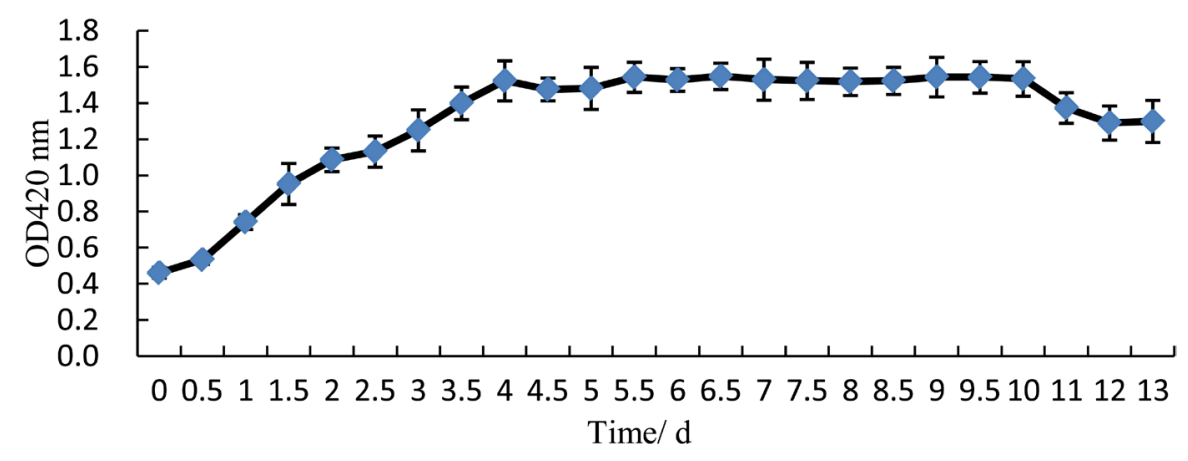

Figure 9. The growth curve of G-94 under the optimal conditions. 
the soil contaminated by petroleum for a long time. The effects of temperature, $\mathrm{pH}$, oil concentration, salt concentration, inoculum amount, $\mathrm{N}$ and $\mathrm{P}$ source on the degradation of oil were studied. Different conditions had great influences on the oil removal rate of G-94. The G-94 has larger biomass when the inoculation amount was $4 \%\left(\mathrm{OD}_{420}=1.739\right)$; Finally, the inoculation amount $4 \%$ was used to do the orthogonal experiment. The optimum $\mathrm{N}$ and $\mathrm{P}$ source was $\left(\mathrm{NH}_{4}\right)_{2} \mathrm{SO}_{4}$ and $\mathrm{K}_{2} \mathrm{HPO}_{4}$, which is basically consistent with the oil medium. Therefore, the temperature, $\mathrm{pH}$ and oil concentration and salt concentration were selected to do orthogonal test to further study the optimum conditions for degrading oil.

The oil removal rate of G- 94 reached to $25.83 \%$ on $10^{\text {th }}$ day. The oil removal rate of G-94 reached $28.56 \%$ on $20^{\text {th }}$ day, increased by $10.57 \%$ compared with $10^{\text {th }}$ day. The oil removal rate of G- 94 reached $30.90 \%$ on $40^{\text {th }}$ day, increased by $8.19 \%$ compared with $20^{\text {th }}$ day. Maybe, the nutrition in the bottle had been consumed with the passage of time, so as to the oil removal rate of increase was not obvious. In order to improve the oil removal rate, nutrition can be added to the bottle; meanwhile, fresh mineral salt liquid media need to be replaced, because degradation of petroleum products by G-94 may be toxic.

Oil degradation is limited by many factors in the soil [14] [15]. The development and utilization of the genetic resources of G-94 for petroleum degradation and their application in the remediation of petroleum contaminated soils should be further studied.

\subsection{Conclusion}

The optimal conditions of oil removal rate of G-94 were $28^{\circ} \mathrm{C}, \mathrm{pH} 7.8$, oil concentration $0.3 \%$, salt concentration $0.5 \%$, inoculation amount $4 \%, \mathrm{~N}$ and $\mathrm{P}$ was $\left(\mathrm{NH}_{4}\right)_{2} \mathrm{SO}_{4}$ and $\mathrm{K}_{2} \mathrm{HPO}_{4}$. Under orthogonal optimum conditions, the oil removal rate of G-94 reached to $25.83 \%, 28.56 \%$ and $30.90 \%$ on the $10^{\text {th }}, 20^{\text {th }}$ and $40^{\text {th }}$ day, respectively.

\section{References}

[1] Hong, J.H., Kim, J., Choi, O.K., Cho, K.S. and Ryu, H.W. (1997) Characterization of A Diesel-Degrading Bacterium, Pseudomonas Aeruginosa IU5, Isolated from Oil-Contaminated Soil in Korea. World Journal of Microbiology and Biotechnology, 21, 381-384. https://doi.org/10.1007/s11274-004-3630-1

[2] García-Alcántara, J.A., Maqueda-Gálvez, A.P., Téllez-Jurado, A., HernándezMartínez, R. and Lizardi-Jiménez, M.A. (2016) Maya Crude-Oil Degradation by A Bacillus Licheniformis Consortium Isolated from a Mexican Thermal Source Using a Bubble Column Bioreactor. Water Air Soil Pollution, 227, 413. https://doi.org/10.1007/s11270-016-3121-7

[3] Mao, X.H., Jiang, R., Xiao, W. and Yu, J.G. (2015) Use of Surfactants for the Remediation of Contaminated Soils: A Review. Journal of Hazardous Materials, 285 , 419. https://doi.org/10.1016/j.jhazmat.2014.12.009

[4] Mulligan, C.N., Yong, R.N. and Gibbs, B.F. (2001) Surfactant-Enhanced Remediation of Contaminated Soil: A Review. Engineering Geology, 60: 371-380. https://doi.org/10.1016/S0013-7952(00)00117-4 
[5] Zhan, Y.B. and Ma, L.A. (2016)Research Progress of Bioremediation of Petroleum Contaminated Soil. Journal of Yangtze University (Natural Science Edition), 13, $52-56$.

[6] Ismail, W., Al-Rowaihi, I.S., Al-Humam, A.A., Hamza, R.Y., El-Nayal, A.M. and Bououdina, M. (2013) Characterization of a Lipopeptide Biosurfactant Produced by A Crude-Oil-Emulsifying Bacillus Sp. I-15. International Biodeterioration \& Biodegradation, 84, 168-178. https://doi.org/10.1016/j.ibiod.2012.04.017

[7] Alsayegh, A., Alwahaibi, Y., Albahry, S., Elshafie, A., Albemani, A. and Joshi, S. (2015) Microbial Enhanced Heavy Crude Oil Recovery through Biodegradation Using Bacterial Isolates from An Omani Oil Field. Microbial Cell Factories, 14, 141-151. https://doi.org/10.1186/s12934-015-0330-5

[8] Leahy, J.G. and Colwell, R.R. (1990) Microbial Degradation of Hydrocarbons in the Environment. Microbiological Reviews, 54, 305-315.

[9] Zhan, Y.B., Ma, L.A., Tao, X,L., He, S.W., Wang, P.Y., Deng, G. and Jiang, T. (2017) Isolation and Identification of Two Strains of Petroleum Degrading Bacteria. Journal of Yangtze University (Natural Science Edition), 14, 61-64.

[10] Zhan, Y.B., Tao, X.L., He, S.W., Song, S.F., Xing, J.J., Li, F.M, Jiang, T. and Ma, L.A. (2017) Isolation, Identification and Degradation Characteristics of Oil Degrading Bacterial Strain. Open Access Library Journal, 4, e4016. https://doi.org/10.4236/oalib.1104016

[11] Wang, Y.L., Zhang, Y.B. and Cao, B. (2014) Process Optimization of Potato Starch Wastewater Treatment by Candida Tropicalis. Industrial Water and Wastewater, 45, 17-21.

[12] Wang, Z., Chen, H.Y., Shen, C.H., Fan, L. and Hu, C. (2006) Xylitol Production with Fermentation of Lees Hydrolysate by Candida Tropicalis. China Brewing, 156, 44-47.

[13] Gui, Q.F., Yao, J.M., Jiang, Y.S. and Zhao, Y.P. (2014) Research Progress of Production of Long Chain Dicarboxylic Acid by Fermentation of Candida Tropicalis. Chemistry and Bioengineering, 31, 17-22.

[14] Lima, D.F., Olivia, O.M.C.D., Geris, R.M.D.S. and Barreto, L.I.S. (2017) Isolation and Selection of Fungi for Degrading Saturated Hydrocarbons, Aromatic Hydrocarbons and NSO Compounds. Open Journal of Yangtze Gas and Oil, 2, 10-26. https://doi.org/10.4236/ojogas.2017.21002

[15] Battu, S. and Pottabathini, V. (2015) Hydrolytic Degradation Study of Lansoprazole, Identification, Isolation and Characterisation of Base Degradation Product. American Journal of Analytical, 6, 145-155. https://doi.org/10.4236/ajac.2015.62013 
Submit or recommend next manuscript to OALib Journal and we will provide best service for you:

- Publication frequency: Monthly

- 9 subject areas of science, technology and medicine

- Fair and rigorous peer-review system

- Fast publication process

- Article promotion in various social networking sites (LinkedIn, Facebook, Twitter, etc.)

- Maximum dissemination of your research work

Submit Your Paper Online: Click Here to Submit

Or Contact service@oalib.com 